\title{
Expertise, Aptitude, and Strategic Remembering
}

\author{
Wolfgang Schneider \\ Max Planck Institute for Psychological Research
}

\author{
David F. Bjorklund \\ Florida Atlantic University
}

\begin{abstract}
SchneIder, Wolfgang, and Bjorklund, David F. Expertise, Aptitude, and Strategic Remembering. Child Development, 1992, 63, 461-473. Second- and fourth-grade children were classified according to their knowledge of soccer (experts vs. novices) and IQ (high vs. low), and given 2 sort-recall tasks. One task included items related to the game of soccer and the other included items from familiar natural language categories. Previous research has shown that expertise in a subject can compensate for low levels of performance on text comprehension tasks. Our results, the first examing the effects of both expertise and intelligence on a strategic memory task, were that soccer expert children recalled more items on the soccer list but not on the nonsoccer list than soccer novice children. However, soccer expertise did not modify a significant effect of IQ level, with high-IQ children recalling more than low-IQ children for all contrasts. Interest in soccer was found to be related to expertise but did not contribute to differences in memory performance. The results demonstrate that the knowledge base plays an important role in children's memory, but that domain knowledge cannot fully eliminate the effects of IQ on sort-recall tasks using domain-related materials. That is, although rich domain knowledge seemed to compensate for low aptitude, in that low-aptitude experts performed at the level of high-aptitude novices, its effects were not strong enough to eliminate performance differences between highand low-aptitude soccer experts.
\end{abstract}

Research over the past decade has clearly demonstrated that developmental differences in children's memory functioning are highly influenced by their familiarity with the to-be-remembered information (e.g., Bjorklund, 1987; Bjorklund, MuirBroaddus, \& Schneider, 1990; Ornstein \& Naus, 1985; Schneider \& Pressley, 1989). Having a more elaborated knowledge base for sets of to-be-remembered items facilitates memory in several ways (Bjorklund, 1987; Pressley, Borkowski, \& Schneider, 1987). First, an elaborated knowledge base can diminish the need for strategy activation (Bjorklund \& Bjorklund, 1985; Chi, 1985). That is, the greater number and strength of associations among items in a highly elaborated knowledge base permits the automatic access of items without the need of effortconsuming strategies. Second, knowledge may provide an enabling condition for strategy use (Ornstein \& Naus, 1985; Rabino- witz, 1984; Schneider, 1986). The greater facility with memory strategies for highly familiar information has been attributed to the fact that children expend less of their limited mental resources in accessing familiar (relative to unfamiliar) items, thus leaving more resources to be applied for the use of strategies (Bjorklund, 1987). Finally, automatic coding of some meaningful materials can prompt more general strategy use. As they automatically process highly related items in a categorical fashion, children may realize that categorization is a good learning strategy (see Best \& Ornstein, 1986; Bjorklund \& Jacobs, 1985).

The most impressive evidence for the powerful effects of knowledge on memory comes from developmental studies using the expert-novice paradigm (e.g., Chi, 1978; Opwis, Gold, Gruber, \& Schneider, 1990; Recht \& Leslie, 1988; Schneider, Körkel, \&

This research was supported by a grant from the Spencer Foundation. Portions of this research were presented at the annual meetings of the American Educational Research Association, Boston, April 1990. Reprint requests should be sent either to Wolfgang Schneider, who is now at the Department of Psychology, University of Würzburg, Wittelsbacherplatz 1, D-8700 Würzburg, FRG, or to David F. Bjorklund, Department of Psychology, Florida Atlantic University, Boca Raton, FL 33431.

[Child Development, 1992, 63, 461-473. (c) 1992 by the Society for Research in Child Development, Inc. All rights reserved. 0009-3920/92/6302-0018\$01.00] 


\section{Child Development}

Weinert, 1989). For example, the studies by Chi (1978) and Opwis et al. (1990) on chess expertise showed that rich domain-specific knowledge enables a child to perform much like an adult expert and better than an adult novice, thus showing a reversal of usual developmental trends. The strong impact of knowledge on memory performance was similarly demonstrated in the study by Schneider et al. (1989). Third-grade soccer experts recalled significantly more units from a text dealing with a soccer game than both fifth-grade and seventh-grade novices. Even more interestingly, the results of this study indicated an elimination of memory differences between children of different intelligence levels or aptitudes when children's degree of knowledge for the to-beremembered information was equated. That is, when the samples of soccer experts and soccer novices were divided into subgroups of high- and low-aptitude children, the results showed that, at each grade level, soccer experts remembered more about the story and showed greater comprehension than soccer novices, independent of aptitude level. In other words, performance was related to domain knowledge, but unrelated to aptitude (see for supporting evidence Recht and Leslie, 1988).

So far, most developmental studies using the expert-novice paradigm have been restricted to tasks dealing with memory for chess or with various aspects of text processing. Although it remains unclear whether effects of the knowledge base on performance on these types of memory tasks are mediated by deliberate strategy use, there is evidence that they occur relatively automatically, thereby diminishing the need for strategy activation (see Opwis et al., 1990). To our knowledge, there is only one study based on the expert-novice paradigm that dealt with the issue of strategic remembering. In this study (Naus \& Ornstein, cited in Ornstein \& Naus, 1985), college-age experts and novices in soccer were presented with two different types of categorized lists to remember. The soccer list was composed of categorized soccer words, whereas the nonsoccer list was constructed from typical taxonomic categories. Naus and Ornstein found differences between experts and novices in both rehearsal and recall with the soccer list. That is, the experts grouped together more items from each soccer category in their rehearsal sets and also recalled more than the soccer novices. As expected, no differences between soccer experts and nov- ices were found for the nonsoccer list. Naus and Ornstein concluded that extended familiarity with the to-be-remembered materials may be critical for the maximally efficient execution of rehearsal strategies.

In the present study, the basic design of Naus and Ornstein was adopted for a different memory paradigm, namely, a sort-recall task, and used with samples of second-grade and fourth-grade children. Like the rehearsal paradigm, the sort-recall task evokes an unambiguous deliberate strategy, that is, sorting according to semantic categories. Children of those grade levels were chosen because there is plenty of evidence that organizational strategies are acquired between ages 8 and 10 (see Schneider \& Pressley, 1989). Given that both second-and fourthgrade children showed more organizational strategies in a sort-recall task when item materials were familiar to them (see Schneider, 1986), we expected positive effects of domain knowledge on behavior and performance on the sort-recall task using soccer words, regardless of age. Preliminary evidence for this assumption was obtained from a pilot study conducted with a sample of 12 fourth-grade soccer experts and novices in order to explore the possibility of ceiling effects for the soccer list. The results showed that soccer experts were more strategic and recalled more items than soccer novices on this task.

One important extension of the original design concerned the consideration of children's aptitude levels. Given the findings of Schneider et al. (1989), we assumed that rich domain-specific knowledge may eliminate the effects of aptitude differences on the sort-recall task with soccer words. That is, we expected high-aptitude and low-aptitude soccer experts to perform at about the same level, and to be more strategic and to recall more items than high- and low-aptitude soccer novices on the sort-recall task using soccer words, regardless of grade. On the other hand, individual differences in intelligence should strongly affect sorting behavior and recall in the sort-recall task using nonsoccer words. Although most studies exploring developmental trends in organizational behavior and recall on sort-recall tasks did not control for effects of verbal intelligence, the few studies that did so found significant intercorrelations among verbal intelligence, sorting, clustering, and recall (e.g., Schneider, Körkel, \& Weinert, 1987).

In a second extension of the original de- 
sign, we explored the effect of interest in soccer on students' performance on the recall task with soccer words. In the traditions of Piaget and Vygotsky, conceptualizations of interest in a domain include both the stored knowledge and value that individuals give tasks in their environment (see Renninger, 1988). Accordingly, a student identified as having an interest in soccer is a person who has a lot of knowledge about soccer and is a person who values soccer above many other things in which he or she is involved. Such a view implies that prior knowledge and interest should be closely correlated. On the other hand, empirical studies investigating the interrelations among prior knowledge and topic interest on schoolchildren's reading and writing performance have found that prior knowledge and topic interest were virtually uncorrelated (see Baldwin, Peleg-Bruckner, \& McClintock, 1985; Hidi \& McLaren, 1989). These authors argued that while their findings conflict with the "common sense" notion that prior knowledge and topic interest should be correlated, they are not surprising because schoolchildren are forced to study a variety of topics whether they like them or not. Only as people get older and increasingly specialized in their activities may interest and knowledge come to correspond closely.

Our study differs from that of Baldwin et al. (1985) and Hidi and McLaren (1989) in that prior knowledge about the relevant topic (i.e., soccer) is not acquired in German schools. Children are not forced to learn anything about soccer. As a consequence, domain knowledge and interest in this topic could be closely related even in children. We decided to assess children's interest in soccer in addition to their knowledge of soccer to explore whether interest and domain knowledge are already closely linked in elementary school children.

A final extension of the original design concerned the inclusion of measures of declarative and procedural metacognitive knowledge (see Pressley et al., 1987). Declarative metacognitive knowledge involves general, factual knowledge concerning memory functions and strategies and is not likely to be affected by a rich knowledge base for a given domain. Procedural knowledge refers to the monitoring and judging of ongoing processes and should reflect the effects of domain knowledge. Since experts are more familiar with the item materials re- lated to their domain than novices, monitoring of ongoing learning processes should be easier for them. These assumptions concerning the relations between declarative and procedural metacognitive knowledge and soccer expertise were empirically confirmed in a recent study by Schneider, Körkel, and Weinert (1990) on text recall and comprehension. While there were no differences in declarative metacognitive knowledge between the groups of experts and novices, significant differences were found for procedural metacognitive knowledge, with experts being more accurate in their predictions of recall and assessments of their own performance than novices.

Thus we assumed that the two components of metacognitive knowledge should have different effects depending on the type of categorized list. Expertise in soccer should influence the accuracy of one's own performance prediction with the soccer list (i.e., procedural metacognitive knowledge). However, soccer experts and novices should not differ in their declarative metacognitive knowledge, that is, their knowledge about the efficiency of sorting strategies. While experts' procedural metacognitive knowledge should be positively correlated with recall of the soccer words, we did not expect to find such a relationship for the declarative metacognitive knowledge component.

However, the pattern of results should be different for the sort-recall task using nonsoccer words. Given that reliable relationships between declarative metacognitive knowledge, organizational strategies, and recall have been reported frequently in the literature (see Schneider \& Pressley, 1989), we expected that declarative metacognitive knowledge should influence both strategic behavior and recall, particularly in the older group. However, we did not expect procedural metacognitive knowledge to be significantly related to either sorting or recall. In general, the performance prediction-memory correlations reported in the literature were positive, but not large (i.e., typically in the .10 to .20 range for categorizable lists; see Schneider \& Pressley, 1989).

\section{Method}

Subjects.-A total of 225 children (121 second graders, 104 fourth graders) from three Munich schools participated in the study. Children were from predominantly middle-class homes. Equal numbers of chil- 


\section{Child Development}

dren in each grade were recruited from the three schools, and approximately equal numbers of boys and girls were included at each age level. There were 52 boys and 52 girls in the subsample of second graders and 60 boys and 61 girls in the fourth-grade subsample. The mean ages for the second- and fourth-grade groups were 7.9 years $(\mathrm{SD}=$ $0.6)$ and 9 years $(S D=0.5)$, respectively. All testing was done in group sessions.

Materials and procedure.-Each child participated in two sessions. In the first session, interest in soccer, soccer knowledge, intelligence, and declarative metacognitive knowledge were assessed. A 12-item questionnaire was used to assess children's interest in soccer and their knowledge about soccer rules and German soccer players. The first two items dealt with children's interest in soccer games shown on TV and their interest in playing soccer. The scale ranged from 0 to 4 , with higher scores indicating higher interest in soccer. Children's ratings were summed across these two items, resulting in an interest scale ranging between 0 and 8 . The interest scale was sufficiently reliable (Cronbach's alpha $=.76$ and .67 for second and fourth graders, respectively). The 10 items dealing with knowledge about soccer were taken from a more comprehensive test of soccer knowledge developed by Pentenrieder (in preparation) that consisted of 45 items. The 10-item scale was chosen because of its high correlation with the total score obtained for Pentenrieder's test battery, $r=.95$. Each item was given a score of 0 or 1 . Children with scores ranging between 5 and 10 were classified as soccer experts, and those with scores below 5 were considered soccer novices. Again, sufficient reliability was found (Cronbach's alpha = .70 and .73 for the second and fourth graders, respectively).

To identify high- and low-aptitude subjects within the groups of soccer experts and novices, children's scores on the verbal aptitude component of cognitive ability tests for second graders (Rieder, 1971) and fourth graders (Heller, Gädike, \& Weinläder, 1985) were used. The internal consistency of both tests was found to be high (Cronbach's alpha $=.89$ and .87 for second and fourth graders, respectively). At each grade level, those subjects scoring above the median of the distribution were classified as high-aptitude children, and those scoring below the median of the distribution were classified as lowaptitude children. As a consequence, four groups were differentiated at each grade level: high-aptitude soccer experts, lowaptitude soccer experts, high-aptitude soccer novices, and low-aptitude soccer novices. Finally, children were presented with a questionnaire tapping their knowledge about organizational strategies. Each of the five items required the children to compare the difficulty of two word lists, one containing clusterable, the other nonclusterable items. Each correct answer was awarded 1 point. For the list item, subjects were additionally asked to justify their decision.

In the second session, conducted in small groups approximately $\mathbf{I}$ week later, children were administered two sort-recall tasks, in counterbalanced order. One task included a list of 24 categorically related items and was adopted from Schneider, Körkel, and Weinert (1987). The stimuli were colored line drawings of common objects. A second list consisted of 20 soccer-related pictures. The names of the objects were printed below the pictures of both lists. The pictures in each list are described in Table 1.

Children were told that they would be shown a set of pictures and should try to do anything that would help them remember the items. Although the possibility of moving pictures around was mentioned, no reference to sorting strategies was made. Children were then given a metal board with one of the sets of items randomly ordered on it. Magnets were affixed to the back of the picture cards so that they would stick to the metal board. A 2-min sorting period was allowed wherein children were given an opportunity to rearrange the items in order to learn them most efficiently, and 2 more min were given for studying the items. A.lmost all of the children moved the pictures around during the sorting period. Children's behavior during sorting and studying was rated, and their arrangements of picture cards were photographed. Three observers rated the degree to which the children organized materials according to semantic categories. They also assessed signs of study behaviors like rehearsal or self-testing. Unfortunately, interrater reliability coefficients were generally low and did not exceed $r=.60$. Consequently, the rating variables were not felt to exhibit sufficient reliability to use them in further analyses. After the study period, the boards and picture cards were removed, and children were asked to predict how many words they would be able to remember correctly. Next, recall was requested. Given that this session was conducted in small 
TABLE 1

Description of the Sets of Strmuli USEd IN THE Sort-Recall Tasks (Soccer and Nonsoccer Lists)

\begin{tabular}{|c|c|c|c|c|c|c|}
\hline \multicolumn{7}{|c|}{ Nonsoccer List } \\
\hline Category $1 \ldots \ldots$. & Cat & Fox & Cow & Zebra & Chicken & Goat \\
\hline Category $2 \ldots . . . .$. & Truck & Train & Bus & Motorcycle & Bike & Airplane \\
\hline Category $3 \ldots \ldots$. & Hammer & Screwdriver & Saw & Shovel & Pliers & Drill \\
\hline Category $4 \ldots . . . .$. & Banana & Cherry & Apple & Pear & Strawberry & Melon \\
\hline \multicolumn{7}{|c|}{ Soccer List } \\
\hline $\begin{array}{l}\text { Category } 1 . \ldots . . . . \\
\text { Category } 2, \ldots \ldots . .\end{array}$ & $\begin{array}{l}\text { Goalie } \\
\text { Penalty kick }\end{array}$ & \multicolumn{2}{|c|}{$\begin{array}{l}\text { Center forward } \\
\text { Goal }\end{array}$} & $\begin{array}{l}\text { Wing } \\
\text { Pass }\end{array}$ & $\begin{array}{l}\text { Midfielder } \\
\text { Corner kick }\end{array}$ & $\begin{array}{l}\text { Defender } \\
\text { Heading }\end{array}$ \\
\hline Category $3 \ldots . . .$. & Soccer ball & \multicolumn{2}{|c|}{ Soccer shoes } & Soccer shirt & Soccer socks & Knee pad \\
\hline Category $4 \ldots . . .$. & Soccer field & \multicolumn{2}{|l|}{ Goal bar } & Goal net & Penalty area & Midline \\
\hline
\end{tabular}

Nore.-Please note that while many of the soccer terms are two words in English, they are one word in German.

groups of 10 to 15 children, oral recall could not be obtained. Children were told that they should write down all the items that they could remember and that they would have about $5 \mathrm{~min}$ time to complete this task.

After the first sort-recall task, a traditional digit-span task was given as an interpolated activity between the two sort-recall tasks. At the end of the session, the second sort-recall task was introduced, using the same procedure as described above for the first sort-recall task.

\section{Results}

The data to be presented were initially examined for possible effects due to school, sex of subjects, and order of task presentation. Since these variables did not show significant effects, the data were collapsed across these three variables in all subsequent analyses.

Recall.-The mean proportions of items recalled for the nonsoccer and soccer lists as a function of grade, expertise, and aptitude level are given in Table 2.

A 2 (grade) $\times 2$ (IQ level) $\times 2$ (expertise) $\times 2$ (task) analysis of variance with repeated measures on the task factor yielded significant main effects of grade, $F(1,215)=$ $148.68, p<.01$; IQ level, $F(1,215)=34.08$, $p<.01$; and expertise, $F(1,215)=9.20, p<$ .01 . In general, older children recalled more than younger children, and more intelligent children recalled more than the less intelligent ones. The main effect of expertise was qualified by an interaction between expertise and task, $F(1,215)=17.55, p<.01$. Subsequent analyses revealed that effects of expertise were restricted to the soccer list (experts, $M=.62$, novices, $M=.44, t(223)$ $=6.83, p<.01$ ); mean proportion of items recalled by soccer experts for the nonsoccer list was .52 , compared to .48 for the soccer novices, $t(223)=1.75$, N.S. This confirmed our assumption that soccer experts recall

TABLE 2

Mean Proportions of Recall as a Function of Task, Grade, EXPERTISE, AND IQ LEVEL

\begin{tabular}{|c|c|c|c|c|}
\hline \multirow[b]{2}{*}{ Grade and TASK } & \multicolumn{2}{|c|}{ SOCCER EXPERTS } & \multicolumn{2}{|c|}{ SOCCER NOVICES } \\
\hline & High IQ & Low IQ & High IQ & Low IQ \\
\hline Grade 2: & $(N=25)$ & $(N=27)$ & $(N=33)$ & $(N=36)$ \\
\hline Nonsoccer list....... & $\begin{array}{c}.46 \\
(.16)\end{array}$ & $\begin{array}{l}.31 \\
(.13)\end{array}$ & $\begin{array}{l}.44 \\
(.14)\end{array}$ & $\begin{array}{l}.35 \\
(.14)\end{array}$ \\
\hline Soccer list ............... & $\begin{array}{c}.53 \\
(.20)\end{array}$ & $\begin{array}{l}.41 \\
(.20)\end{array}$ & $\begin{array}{l}.44 \\
(.14)\end{array}$ & $\begin{array}{l}.31 \\
(.12)\end{array}$ \\
\hline Grade 4: & $(N=29)$ & $(N=27)$ & $(N=24)$ & $(N=24)$ \\
\hline Nonsoccer list....... & $\begin{array}{c}.66 \\
(.18)\end{array}$ & $\begin{array}{l}.55 \\
(.18)\end{array}$ & $\begin{array}{l}.62 \\
(.17)\end{array}$ & $\begin{array}{l}.60 \\
(.13)\end{array}$ \\
\hline Soccer list ................ & $\begin{array}{l}.76 \\
(.15)\end{array}$ & $\begin{array}{c}.63 \\
(.16)\end{array}$ & $\begin{array}{l}.62 \\
(.11)\end{array}$ & $\begin{array}{l}.51 \\
(.15)\end{array}$ \\
\hline
\end{tabular}

NoTE.-Standard deviations are in parentheses. 


\section{Child Development}

more items than soccer novices on a sortrecall task using soccer items, regardless of grade level.

However, our expectation that rich domain-specific knowledge may also eliminate the effects of aptitude on the sort-recall task with soccer words was not supported by the data. High-aptitude experts outperformed low-aptitude experts, and highaptitude novices performed significantly better than low-aptitude novices.

One problem with our definition of soccer experts and novices was that those subjects scoring above the median of the overall distribution in the soccer knowledge test were classified as soccer experts, and those with scores below the median of the distribution were classified as soccer novices. As a consequence, more fourth graders (56 out of 104; 32 boys and 24 girls) than second graders (52 out of $121 ; 29$ boys and 23 girls) were identified as soccer experts, and several fourth-grade subjects showing only average performance on the soccer knowledge test were included in the group of soccer experts.

The possibility that our definition of expertise in this study could have contributed to our finding that verbal intelligence predicted memory performance for the soccer lists even for the soccer experts was investigated in two subsequent analyses that modified how soccer expertise was defined. In one analysis, those subjects belonging to the upper quartile of the distribution in the soccer knowledge test were contrasted with those in the lowest quartile, making the distinction between soccer experts and novices extreme. In a second analysis, soccer expertise was defined by a median split separately at each grade, making for approximately equal numbers of experts and novices at each grade level. Reanalyses of the recall data using both the extreme quartiles and grade-defined definitions of expertise each produced comparable results to those reported above. The main effect of IQ level was significant in each of these analyses, as was the expertise $\times$ task interaction: highIQ soccer experts recalled significantly more on both lists than low-IQ soccer experts. However, the difference found between the two groups was significantly greater for the soccer list than for the nonsoccer list. ${ }^{1}$

Organization during sorting and recall.-In order to assess the degree to which sorting during encoding and clustering during recall corresponded to the adult categories for the two lists, ratio of repetition (RR) scores with a maximum value of slightly less than 1.0 and a minimum value of 0 (see Bousfield, 1953) were computed. To compute the RR scores, a ratio was obtained of the number of repetitions observed in a child's sort (or clustering during recall) to the number of possible repetitions. The $R R$ measure has been shown statistically to be relatively independent of the level of total recall (see Murphy \& Puff, 1982).

The number of categorical repetitions (i.e., either horizontal or vertical juxapositions of exemplars from the same taxonomic group) was counted for each photograph (see Kee \& Bell, 1981). As all subjects who manipulated the items sorted them by row, there was no problem with using the RR score as an index of sorting behavior. Mean RR clustering scores for sorting during encoding as a function of grade, expertise, and IQ level are given in Table 3.

A 2 (grade) $\times 2$ (IQ level) $\times 2$ (expertise) $\times 2$ (task) analysis of variance with repeated measures on the task factor carried out on the sorting scores yielded main effects of grade, $F(1,215)=36.08, p<.01$, and task, $F(1,215)=32.32, p<.01$. Further, the interaction between grade and task was significant, $F(1,215)=11.60, p<.01$. Older children sorted according to the adult categories more than younger children, sort

\footnotetext{
${ }^{1}$ For the analysis in which expertise was defined by median splits separately at each grade, the main effect of IQ level was significant, $F(1,215)=37.07, p<.01$, as was the expertise $\times$ task interaction, $F(1,215)=11.36, p<.01$. Again, high-IQ soccer experts recalled significantly more on the soccer list (.64) than low-IQ soccer experts $(.47), t(106)=5.78, p<.01$. Although the high-IQ soccer experts (.55) also outperformed low-IQ soccer experts (.46) on the nonsoccer list, $t(106)=2.79, p<.01$, the mean recall difference between the two groups was less pronounced for this list. A similar pattern of results was obtained for the analysis in which the soccer expertise/novice distinction was defined using the extreme quartiles. The main effect of IQ level was significant, $F(1,96)=7.72, p<.01$, as was the expertise $\times$ task interaction, $F(1,96)=28.7$, $p<.001$. As in the other analyses, the recall of the high-IQ soccer experts for the soccer list (.73) was significantly higher than that of the low-IQ soccer experts $(.58), t(46)=3.71, p<.01$. For the nonsoccer list, however, the mean recall difference between the two groups was much smaller and not significant: .56 vs .53 for the high-IQ and low-IQ experts, $t(46)=1.43, p>.05$.
} 
TABLE 3

Mean Sohting and Clustering Scores, as a Function of Task, GRADE, AND IQ LEVEL

\begin{tabular}{|c|c|c|c|c|}
\hline \multirow[b]{2}{*}{ Grade AND TaSK } & \multicolumn{2}{|c|}{ SOCCER EXPERTS } & \multicolumn{2}{|c|}{ SOCCER NOVICES } \\
\hline & High IQ & Low IQ & High IQ & Low IQ \\
\hline \multicolumn{5}{|l|}{ Grade 2: } \\
\hline Sorting nonsoccer list.............. & $\begin{array}{l}.38 \\
(.28)\end{array}$ & $\begin{array}{l}.30 \\
(.24)\end{array}$ & $\begin{array}{l}.46 \\
(.31)\end{array}$ & $\begin{array}{l}.40 \\
(.28)\end{array}$ \\
\hline 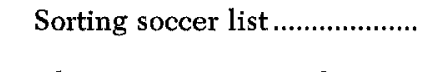 & $\begin{array}{l}.34 \\
(.33)\end{array}$ & $\begin{array}{l}.22 \\
(.12)\end{array}$ & $\begin{array}{l}.28 \\
(.18)\end{array}$ & $\begin{array}{l}.31 \\
(.16)\end{array}$ \\
\hline Clustering nonsoccer list ....... & $\begin{array}{l}.34 \\
(.20)\end{array}$ & $\begin{array}{l}.30 \\
(.21)\end{array}$ & $\begin{array}{l}.40 \\
(.24)\end{array}$ & $\begin{array}{l}.40 \\
(.21)\end{array}$ \\
\hline Clustering soccer list .............. & $\begin{array}{c}.37 \\
(.18)\end{array}$ & $\begin{array}{c}.24 \\
(.21)\end{array}$ & $\begin{array}{c}.29 \\
(.17)\end{array}$ & $\begin{array}{l}.23 \\
(.18)\end{array}$ \\
\hline \multicolumn{5}{|l|}{ Grade 4: } \\
\hline Sorting nonsoccer list.............. & $\begin{array}{l}.66 \\
(.29)\end{array}$ & $\begin{array}{l}.67 \\
(.26)\end{array}$ & $\begin{array}{l}.67 \\
(.30)\end{array}$ & $\begin{array}{l}.58 \\
(.30)\end{array}$ \\
\hline Sorting soccer list ...................... & $\begin{array}{l}.40 \\
(.24)\end{array}$ & $\begin{array}{l}.39 \\
(.19)\end{array}$ & $\begin{array}{c}.42 \\
(.20)\end{array}$ & $\begin{array}{l}.41 \\
(.19)\end{array}$ \\
\hline Clustering nonsoccer list ....... & $\begin{array}{l}.73 \\
(.26)\end{array}$ & $\begin{array}{l}.57 \\
(.23)\end{array}$ & $\begin{array}{l}.59 \\
(.22)\end{array}$ & $\begin{array}{l}.58 \\
(.20)\end{array}$ \\
\hline Clustering soccer list .............. & $\begin{array}{l}.48 \\
(.17)\end{array}$ & $\begin{array}{l}.33 \\
(.12)\end{array}$ & $\begin{array}{l}.41 \\
(.19)\end{array}$ & $\begin{array}{l}.39 \\
(.21)\end{array}$ \\
\hline
\end{tabular}

NOTE.-Sorting/clustering scores larger than .30 are significantly different from chance level. Standard deviations are in parentheses.

scores were higher for the nonsoccer list than for the soccer list, and the difference found between sorting scores for the soccer and nonsoccer lists was significant at each grade but greater for the fourth graders, $t(104)=8.96, p<.01$, than for the second graders, $t(119)=5.15, p<.01$.

A similar pattern of results was found for the clustering scores. A 2 (grade) $\times 2$ (IQ level) $\times 2$ (expertise) $\times 2$ (task) analysis of variance with repeated measures on the task factor yielded significant main effects of grade, $F(1,215)=45.41, p<.01$, task, $F(1,215)=32.32, p<.01$, and IQ level, $F(1,215)=6.68, p<.05$. Further, the interaction between grade and task was significant, $F(1,215)=6.91, p<.01$. Older children clustered more according to the adult categories than younger children, clustering scores were higher for the nonsoccer list than for the soccer list, and the difference found between clustering scores for the soccer and nonsoccer lists was significant at each grade but greater for fourth graders, $t(104)=6.38, p<.01$, than for second graders, $t(223)=4.23, p<.01$.

Contrary to expectations, effects of domain knowledge were found neither for sorting nor for clustering on the soccer list. Thus there was no indication that soccer knowl- edge facilitated the use of sorting or clustering when the task consisted of memorizing soccer items. One possible explanation for this unexpected finding could be that levels of sorting and clustering were mostly significantly higher than chance expectancy, at least in fourth graders. Apparently, many fourth graders used the organizational strategy deliberately and were able to apply the strategies in both task settings. (Clustering scores larger than .31 are significantly different from chance level, which is .22 and .21 for the soccer and nonsoccer lists, respectively.) Support for this argument comes from Table 4, which shows the intercorrelations among organizational strategies, recall, and task-specific metamemory as a function of grade and expertise.

As noted by many researchers in the field (see Frankel \& Rollins, 1982; Hasselhorn, 1990; Schneider, 1986), deliberate strategy use is reflected by significant correlations between sorting and clustering during recall on the one hand and between clustering and recall on the other hand. As nine out of the 12 intercorrelations involving these three variables are reliable (see Table 4 ), there is reason to assume that many children in our sample used the strategy on both occasions. To assess the impact of domain knowledge on interrelations among sorting, 
TABLE 4

INTERCORRELATIONS AMONG SORTING, CLUSTERING DURING

Recall, Recall, and Declarative Metamemeory, as a FUNCTION OF GRADE

\begin{tabular}{|c|c|c|c|}
\hline & Sorting & Clustering & Metamemory \\
\hline \multicolumn{4}{|l|}{ Grade $2(N=121)$} \\
\hline 1. Free recall ......... & $\begin{array}{l}.36^{*} \\
(.04)\end{array}$ & $\begin{array}{l}.33^{*} \\
\left(.35^{*}\right)\end{array}$ & $\begin{array}{l}.20 \\
(.30 *)\end{array}$ \\
\hline 2. Sorting ............... & & $\begin{array}{l}.42 * \\
(.15)\end{array}$ & $\begin{array}{l}.12 \\
(.04)\end{array}$ \\
\hline 3. Clustering.......... & & & $\begin{array}{l}.12 \\
(.16)\end{array}$ \\
\hline 4. Metamemory .... & & & $\cdots$ \\
\hline \multicolumn{4}{|l|}{ Grade $4(N=104)$ : } \\
\hline 1. Free recall ......... & $\begin{array}{l}.45^{*} \\
(.19)\end{array}$ & $\begin{array}{l}.33^{*} \\
\left(.29^{*}\right)\end{array}$ & $\begin{array}{l}.32^{*} \\
\left(.12^{*}\right)\end{array}$ \\
\hline 2. Sorting ................ & & $\begin{array}{l}.38^{*} \\
\left(.36^{*}\right)\end{array}$ & .11 \\
\hline 3. Clustering......... & & & $\begin{array}{l}.05 \\
(.13)\end{array}$ \\
\hline 4. Metamemory .... & & & $\ldots$ \\
\hline
\end{tabular}

Note.-Asterisks denote correlations significant at the $p=.05$ level. Intercorrelations for soccer items are given in parentheses.

clustering, and recall of the soccer list, correlations among these variables were computed as a function of grade and expertise (see Table 5).

As can be seen from Table 5 , interrelations among sorting, clustering, and recall were generally low and unreliable for the second graders, regardless of expertise. Although the correlation coefficients tended to be higher for the second-grade experts, as compared to the novices, only the correlation between sorting and clustering reached statistical significance. It should be noted, however, that the difference in correlations between sorting and clustering obtained for the second-grade experts and novices was not significant $(z=0.95 ; p>.05)$. The pattern of results found for the fourth graders was more clear-cut in that reliable intercorrelations among sorting, clustering, and recall were found for the experts but not for the novices. Tests of the significance of the differences between the correlations obtained for the experts and novices revealed that two out of the three correlations, namely, the correlations between sorting and clustering and clustering and recall, differed significantly between the two groups $(z=2.26$ and 2.25 for the correlations between sorting and clustering and clustering and recall, respectively; all $p$ 's $<.05$ ). Apparently, it was only for the fourth-grade experts that sorting behavior influenced subse- quent clustering and recall of the soccer materials. Although the absolute amount of sorting did not differ between fourth-grade experts and novices, signs of strategic behavior on the soccer task were found only for the fourth-grade experts but not for the novices.

Interest and domain knowledge.Second graders $(M=4.62)$ and fourth graders $(M=4.75)$ did not differ regarding their interest in soccer, $t(223)=0.54, p>.05$. However, when the measures of interest and knowledge about soccer were intercorrelated, different findings emerged as a function of grade. Although the correlation was statistically significant for each grade, it was significantly lower for second graders than for fourth graders $(r$ 's $=.35$ and .67 , respectively, $z=3.28, p<.01$ ). It appears, then, that interest in soccer and knowledge about soccer are not closely related in young elementary school children. Second graders may be very interested in soccer but do not know much about soccer rules and events, and vice versa. On the other hand, the correlational pattern indicates a developmental trend showing that interest and domain knowledge covary considerably in advanced elementary school children.

A 2 (grade) $\times 2$ (expertise) $\times 2$ (interest level) $\times 2$ (task) analysis of variance with repeated measures on the task factor using proportion of items recalled as the depen- 


\section{TABLE 5}

INTERCORRELATIONS AMONg SORTING, CluStering DURING Recall, aND Recall on tHE SOCCER LIST as a FunCtion of Grade and EXPERTISE

\begin{tabular}{|c|c|c|}
\hline & Sorting & Clustering \\
\hline \multicolumn{3}{|l|}{ Grade 2: } \\
\hline \multicolumn{3}{|l|}{ 1. Free recall: } \\
\hline Experts $(N=52)$ & .08 & $.57^{*}$ \\
\hline Novices $(N=69) \ldots \ldots$. & -.04 & .23 \\
\hline \multicolumn{3}{|c|}{ 2. Sorting: } \\
\hline Experts $(N=52) \ldots \ldots$. & & .27 \\
\hline Novices $(N=69)$ & & .15 \\
\hline \multicolumn{3}{|l|}{ 3. Clustering: } \\
\hline Experts $(N=52) \ldots \ldots$ & & $\ldots$ \\
\hline Novices $(N=69)$ & & $\ldots$ \\
\hline \multicolumn{3}{|l|}{ Grade 4: } \\
\hline \multicolumn{3}{|l|}{ 1. Free recall: } \\
\hline Experts $(N=56) \ldots \ldots$ & $.31^{*}$ & $.39^{*}$ \\
\hline Novices $(N=48) \ldots \ldots$ & .10 & .23 \\
\hline \multicolumn{3}{|l|}{ 2. Sorting: } \\
\hline Experts $(N=56)$ & & $.57^{*}$ \\
\hline Novices $(N=48) \ldots \ldots$. & & .22 \\
\hline \multicolumn{3}{|l|}{ 3. Clustering: } \\
\hline Experts $(N=56)$ & & $\cdots$ \\
\hline Novices $(N=48) \ldots \ldots$. & & $\ldots$ \\
\hline
\end{tabular}

NoTE.-Asterisks denote correlations significant at the $p=.05$ level.

dent variable yielded significant main effects of grade, $F(1,215)=112.07, p<.01$, and expertise, $F(1,215)=7.83, p<.01$. Interestingly, there was no significant main effect of interest level (high vs. low) operationalized via median split, showing that domain knowledge and not interest influenced recall patterns in the two sort-recall tasks. Similar results were obtained for analyses assessing the effects of interest for the sorting and clustering measures.

Effects of metacognitive knowledge.As noted below, the performance prediction paradigm was used to assess children's procedural metacognitive knowledge. Accuracy of performance prediction was assessed by computing the absolute difference between prediction and recall. Although the use of this measure entails some methodological problems (see Hasselhorn \& Hager, 1989, for a more detailed discussion), we considered it to be acceptable in the present study.

A 2 (grade) $\times 2$ (IQ level) $\times 2$ (expertise) $\times 2$ (task) analysis of variance with repeated measures on the task factor using accuracy in performance prediction as the dependent variable yielded main effects of grade, $F(1,215)=7.55, p<.01$, and task, $F(1,215)=9.19, p<.01$. Fourth graders' average accuracy scores $(M=3.78, \mathrm{SD}=2.77)$ were better than those of the second graders ( $M=5.13, \mathrm{SD}=4.68)$, and prediction accuracy was generally better for the nonsoccer list $(M=3.88, \mathrm{SD}=3.55)$ than for the soccer list $(M=5.02, \mathrm{SD}=3.90)$. In addition, the interaction between task and expertise was significant, $F(1,215)=3.89, p<.05$. As expected, soccer experts $(M=4.32)$ were significantly more accurate than soccer novices $(M=5.58)$ in predicting their performance on the sort-recall task using soccer items, $t(223)=2.88, p<.05$. There was no effect of soccer expertise on the accuracy of performance prediction in the sort-recall task using nonsoccer materials. Our measure of prediction accuracy does not give information on the amount of over- versus underestimation found in each age group. Theoretically, all children could have overestimated their abilities on every task. The expertise $\times$ task interaction would then emerge simply because the cell in which recall performance was highest was the "soccer list-soccer experts" cell. If that were the case, the data would have little to say about procedural metamemory and expertise. A closer inspection of the direction of the prediction error showed that this was not the case. Although most second graders overestimated their performance on both memory tasks ( $54 \%$ ad $67 \%$ on the nonsoccer and soccer lists, respectively), about $25 \%$ underestimated their performance on both tasks. Fourth graders tended to overestimate performance on the soccer list in $55 \%$ of the cases but were less optimistic regarding performance on the nonsoccer list (rate of overestimates: 39\%). In this age group, proportions of underestimates for the soccer and nonsoccer lists were $26 \%$ and $43 \%$, respectively. Accordingly, no general tendency towards overestimation was found.

A 2 (grade) $\times 2$ (IQ level) $\times 2$ (expertise) analysis of variance on declarative metacognitive knowledge revealed main effects of grade, $F(1,215)=10.63, p<.01$, and IQ level, $F(1,215)=6.11, p<.01$. Higher metamemory scores were found for fourth graders than for second graders $(M=2.45$ vs. $M=$ 1.92), $t(220)=3.21, p<.01$, and for the more intelligent children as compared to the less intelligent children $(M=2.55$ vs. $M=$ $2.00), t(220)=3.10, p<.01$.

The results of the correlational analyses showed that the effects of declarative metacognitive knowledge on strategy use and recall differed as a function of grade and task. As can be seen from Table 4, second graders' declarative knowledge was significantly cor- 
related with recall of the soccer items but not with recall of the nonsoccer list, whereas the reverse was true for the fourth graders. Subsequent analyses revealed that the difference between the two correlations was significant for the fourth graders $(z=1.69$, $p<.05)$ but insignificant for the second graders $(z=0.81, p>.05)$. Thus our expectations regarding the impact of declarative metacognitive knowledge were confirmed only for the older subjects and did not hold true for the younger children.

\section{Discussion}

In the present study, an attempt was made (1) to replicate the findings from developmental studies based on the expert/ novice paradigm (Chi, 1978; Opwis et al., 1990; Schneider et al., 1989) by using a different experimental paradigm (i.e., a sortrecall task), (2) to assess the extent to which expertise can compensate for individual differences in intelligence on a strategic memory task, (3) to investigate the impact of procedural and declarative metacognitive knowledge on strategic behavior and recall, and (4) to examine whether interest plays a role in performance.

Our findings concerning the issue of replicability demonstrate a substantial impact of soccer knowledge on performance in a sort-recall task using soccer materials, regardless of grade. Thus the findings of this study do replicate those of the earlier studies. However, effects of the knowledge base found for our sort-recall task were not as strong as those reported in the earlier studies. First, unlike the studies by Chi (1978), Opwis et al. (1990), and Schneider et al. (1989), no reversal of developmental trends was observed. That is, second-grade soccer experts did not outperform fourth-grade soccer novices on the sort-recall task using soccer items. Second, the effect of domainspecific knowledge was not strong enough to eliminate the effects of aptitude. Within each grade, high-aptitude soccer experts performed better than low-aptitude soccer experts. However, the finding that the performance of the low-aptitude experts was equal to that of the high-aptitude novices indicates that expertise compensated for not having high aptitude.

Contrary to our expectations, the soccer experts' superior recall was not generally accompanied by higher levels of taxonomic organization. Many children in both age groups were able to use the sorting strategy on both the traditional sort-recall task and the one using soccer materials. However, a closer inspection of the interrelations among sorting, clustering, and recall on the soccer list showed that while correlations among these three variables were not reliable for the second- and fourth-grade novices, they were statistically significant for the fourthgrade soccer experts. A comparison of the sorting scores of the fourth-grade experts and novices revealed that even the novices were obviously able to sort the soccer items into categories such as player type, kind of move, equipment, and field location. However, it was only for the experts that individual differences in sorting behavior corresponded with individual differences in recall organization and recall. That is, those fourth-grade experts who used organizational strategies during study were more likely to apply the same organizational strategies at recall, as compared with the fourthgrade novices. Accordingly, there was at least modest support for the assumption that domain knowledge facilitates effective strategy use. In general, however, individual differences in strategy use did not account for much of the variance in recall of the soccer items.

When predicting that experts would be more strategic than novices on the soccer sort-recall task, we assumed that rich domain knowledge would provide a facilitating condition for strategy use, thus enabling the soccer experts to carry out organizational strategies more efficiently than soccer novices. This hypothesis was mainly based on the findings reported by Naus and Ornstein (in Ornstein \& Naus, 1985) for adult soccer experts (see above). Although this assumption could be partially confirmed, our results also indicate that effects of domain knowledge on recall may not only be mediated by strategies but could also be a direct consequence of experts' richer knowledge base. That is, a closer examination of the recall protocols showed that the source of the expert-novice differences was not only in the number of categories searched $(M=3.82$ vs. 3.55, $t(223)=3.82, p<.05$ for the experts and novices, respectively), but also in the number of items within a category retrieved ( $M$ $=3.08$ vs. $2.20, t(223)=6.14, p<.05)$. Thus, our findings also support the other assumption outlined in the introduction of this paper, namely, that rich domain knowledge can diminish the need for strategy use. That is, even when tasks require the use of strategies, experts do not have to be more strategic 
than novices in order to do better on sortrecall tasks using soccer items.

Regarding the influence of declarative and procedural metacognitive knowledge on memory performance, our expectations were only partially confirmed. There were only moderate intercorrelations between declarative metacognitive knowledge and recall at each age and for each item list. The expectation that declarative knowledge should correlate with recall on the nonsoccer list was confirmed only for the fourth-grade children. Although the expected expertise $\times$ task interaction for procedural metacognitive knowledge was found to be reliable, the interaction accounted for little of the variance. Individual differences in declarative and procedural metacognitive knowledge seemed to have a rather modest impact on memory performance in our sort-recall tasks.

As to the interaction of interest and knowledge, our findings for the younger age group seem to conflict with the "common sense" notion that interest and domain knowledge should be highly intercorrelated. However, this result does not seem very surprising as far as young children are concerned, and has been reported previously by researchers working in the area of text processing (e.g., Baldwin et al., 1985; Hidi \& McLaren, 1989). One possible explanation brought up by these authors is that in schools, children must learn to deal with a variety of topics whether they like them or not. Only as they get older and increasingly specialized in their motivation do their interests and knowledge begin to correspond more closely.

While such a developmental trend was also found in our data, the only moderate correlation between interest and domain knowledge found for our young subjects is certainly not due to the fact that they all play soccer, whether they like it or not. Instead, what we typically find in this age group is a large number of children who seem to be very interested in playing soccer but who either do not care about or do not understand the complicated rules. These subjects represent a subsample that can be used to assess the effects of interest and knowledge on memory performance separately.

We assessed the effects of knowledge and interest separately and did not find any independent effect of interest. Although interest is related to expertise, at least for the older children, there is no independent effect on memory performance beyond that contributed by knowledge. Our results confirm those of Baldwin et al. (1989) and Hidi and McLaren (1989) in that domain knowledge seems to influence cognitive performance considerably more than interest in the domain.

One theoretical problem with our approach is that children were classified as experts or novices on the basis of a median score. Accordingly, not all of the children referred to as "experts" had a truly rich knowledge base. Thus, expertise must be used in a relative sense here. As noted above, however, we found that results obtained for the "experts" and "novices" defined on the basis of a median score generalize to a comparison of extreme groups of soccer experts and novices. That is, similar results were found when children whose performance on the soccer test fell within the top quartile of scores and the bottom quartile of scores were compared. Of course, one may still argue that above-average performance on a 10 -item soccer questionnaire does not necessarily indicate a rich knowledge base in the domain of soccer. However, there is at least indirect evidence that the children scoring high on our soccer questionnaire knew a lot about soccer. As indicated above, the items of our soccer questionnaire were selected from a comprehensive questionnaire developed by Pentenrieder (in preparation) because of their high correlation with the total score of Pentenrieder's battery $(r=.95)$. We know from Pentenrieder's data that those of Pentenrieder's subjects (i.e., 610 fourth- and sixthgrade children) who got most of our 10 items right also scored very high on the 38-item soccer test. Thus, there seems reason to assume that those children whose performance fell within the top quartile of scores on our soccer questionnaire knew a lot about soccer.

Theoretically, the reason that aptitude was found to be related to domain-specific memory in this study but not in the previous ones could have to do with the use of a written recall procedure. That is, high verbal second- and fourth-grade children may be so much more competent at writing names for things than their low verbal peers that they enjoy an advantage over them on any test in which this skill is a component. Although this assumption seems intuitively convincing, the text recall data reported by Schneider et al. (1990) do not support such a view. These authors also used a written recall procedure but did not find significant differ- 
ences between the recall protocols of highand low-aptitude soccer experts.

One major difference between the work by Schneider et al. (1990) and the present study concerns the type of recall: Whereas gist recall was the dependent variable in the study by Schneider et al. (1990), verbatim recall was required in this study. Given that aptitude and memory capacity are positively correlated (see Schneider et al., 1987), it could be possible that high-aptitude children's superior memory capacity contributed to the recall differences found between high- and low-aptitude soccer experts in this study. Effects of memory capacity, however, may be less important when recall of the main ideas of a story is the unit of analysis.

Taken together, the results of this study indicate that the findings from those developmental studies on knowledge effects based on paradigms dealing with text processing or memory for chess did not completely generalize to the sort-recall paradigm. Although significant direct and indirect effects of the knowledge base can also be demonstrated for this type of memory task, it appears that they are less powerful than those obtained for memory paradigms where a rich knowledge base may diminish the need for strategy activation. Importantly, when deliberate strategies play a role in task performance, being an expert does not eliminate the effects attributable to individual differences in intelligence.

\section{References}

Baldwin, R. S., Peleg-Bruckner, Z., \& McClintock, A. H. (1985). Effects of topic interest and prior knowledge on reading comprehension. Reading Research Quarterly, 20, 497-504.

Best, D. L., \& Ornstein, P. A. (1986). Children's generation and communication of mnemonic organizational strategies. Developmental Psychology, 22, 845-853.

Bjorklund, D. F. (1987). How age changes in knowledge base contribute to the development of children's memory: An interpretive review. Developmental Review, 7, 93-130.

Bjorklund, D. F., \& Bjorklund, B. R. (1985). Organization versus item effects of an elaborated knowledge base on children's memory. Developmental Psychology, 21, 1120-1131.

Bjorklund, D. F., \& Jacobs, J. W. (1985). Associative and categorical processes in children's memory: The role of automaticity in the development of organization in free recall. Jour- nal of Experimental Child Psychology, 39, 599-617.

Bjorklund, D. F., Muir-Broaddus, J. E., \& Schneider, W. (1990). The role of knowledge in the development of children's strategies. In D. F. Bjorklund (Ed.), Children's strategies: Contemporary views of cognitive development (pp. 93-128), Hillsdale, NJ: Erlbaum.

Bousfield, W. A. (1953). The occurrence of clustering in the recall of randomly arranged associates. Journal of Genetic Psychology, 49, 229-240.

Chi, M. T. H. (1978). Knowledge structures and memory development. In R. S. Siegler (Ed.), Children's thinking: What develops? (pp. 73-96). Hillsdale, NJ: Erlbaum.

Chi, M. T. H. (1985). Interactive roles of knowledge and strategies in the development of organized sorting and recall. In S. F. Chipman, J. W. Segal, \& R. Glaser (Eds.), Thinking and learning skills: Research and open questions (Vol. 2, pp. 457-483). Hillsdale, NJ: Erlbaum.

Frankel, M. T., \& Rollins, H. A. (1982). Agerelated differences in clustering: A new approach. Journal of Experimental Child Psychology, 34, 113-122.

Hasselhorn, M. (1990). The emergence of strategic knowledge activation in categorical clustering during retrieval. Journal of Experimental Child Psychology, 50, 59-80.

Hasselhorn, M., \& Hager, W. (1989). Prediction accuracy and memory performance: Correlational and experimental tests of a metamemory hypothesis. Psychological Research, 51, $147-152$.

Heller, K. A., Gädike, A. K., \& Weinläder, H. (1985). Kognitiver Fähigkeitstest für 4. bis 13. Klassen (KFT 4-13) (2d ed.). Weinheim: Beltz.

Hidi, S., \& McLaren, J. (1989). The effect of topic and theme interestingness on the production of school expositions. In H. Mandl, E. De Corte, N. Bennett, \& H. F. Friedrich (Eds.), Learning and instruction in an international context (Vol. 2.2, pp. 295-308). Oxford: Pergamon.

Kee, D. W., \& Bell, T. S. (1981). The development of organizational strategies in the storage and retrieval of categorical items in free-recall learning. Child Development, 52, 1163-1171.

Murphy, M. D., \& Puff, C. R. (1982). Free recall: Basic methodology and analyses. In C. R. Puff (Ed.), Handbook of research methods in human memory and cognition (pp. 99-128). New York: Academic Press.

Opwis, K., Gold, A., Gruber, H., \& Schneider, W. (1990). Zum Einfluß von Expertise auf Gedächtnisleistungen und ihre Selbsteinschätzung bei Kindern und Erwachsenen [The impact of expertise on memory performance and 


\section{Schneider and Bjorklund}

performance prediction in children and adults]. Zeitschrift für Entwicklungspsychologie und Pädagogische Psychologie, 22, 207-224.

Ornstein, P. A., \& Naus, M. J. (1985). Effects of the knowledge base on children's memory strategies. In H. W. Reese (Ed.), Advances in child development and behavior (Vol. 19, pp. 113-148). Orlando, FL: Academic Press.

Pressley, M., Borkowski, J. G., \& Schneider, W. (1987). Cognitive strategies: Good strategy users coordinate metacognition and knowledge. In R. Vasta \& G. Whitehurst (Eds.), Annals of child development (Vol. 5, pp. 89-129). New York: JAI.

Rabinowitz, M. (1984). The use of categorical organization: Not an all-or-none situation. Journal of Experimental Child Psychology, 38, 338-351.

Recht, D. R., \& Leslie, L. (1988). Effect of prior knowledge on good and poor readers' memory of text. Journal of Educational Psychology, 80, 16-20.

Renninger, K. A. (April, 1988). Effects of interest and noninterest on student performance with tasks of mathematical word problems and reading comprehension. Paper presented at the annual meetings of the American Educational Research Association, New Orleans, LA.
Rieder, O. (1971). Allgemeiner Schulleistungstest für 2. Grundschulklassen AST 2 [General test of cognitive abilities for grade 2]. Weinheim: Beltz.

Schneider, W. (1986). The role of conceptual knowledge and metamemory in the development of organizational processes in memory. Journal of Experimental Child Psychology, 42, 218-236.

Schneider, W., Körkel, J., \& Weinert, F. E. (1987). The effects of intelligence, self-concept, and attributional style on metamemory and memory behavior. International Journal of Behavioral Development, 10, 281-299.

Schneider, W., Körkel, J., \& Weinert, F. E. (1989). Domain-specific knowledge and memory performance: A comparison of high- and lowaptitude children. Journal of Educational Psychology, 81, 306-312.

Schneider, W., Körkel, J., \& Weinert, F. E. (1990). Expert knowledge, general abilities, and text processing. In W. Schneider \& F. E. Weinert (Eds.), Interactions among aptitudes, strategies, and knowledge in cognitive performance (pp. 235-251). New York: SpringerVerlag.

Schneider, W., \& Pressley, M. (1989). Memory development between 2 and 20. New York: Springer-Verlag. 
This document is a scanned copy of a printed document. No warranty is given about the accuracy of the copy. Users should refer to the original published version of the material. 